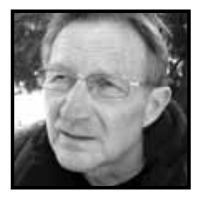

\title{
The Influence of Nature on Learning:The Case of Fosen Folk School in Norway ${ }^{1}$
}

\author{
Ronald Hansen, Western University
}

\begin{abstract}
This institutional ethnography provides an intensive, holistic description and compelling story of a different way of learning. It creates insight and understanding about learning that is not possible in the confines of school systems driven and governed by global economics. How do the instructors, headmaster, and students at Fosen Folk School in Norway teach/learn in a non-academic residential school? Their way of learning helps explain the complex territory between the instincts and tendencies that govern our learning when it is unfettered by institution/government standards, and the norms/values which characterize what is thought, within the formal learning system, to constitute effective teaching/learning. The relationship of self to people, nature, and the environment becomes discernible, understandable.
\end{abstract}

\section{Folk Schools}

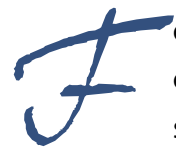

olk schools are one-year residential institutes offering a variety of exciting non-traditional and non-academic subjects, as well as academic subjects. The idea of folk schools is learning for life, an opportunity to grow both individually, socially, and academically in small learning communities. All students live on campus in close contact with staff and their fellow students. One important part of the folk school experience is to form a community, in and out of class.

The folk schools do not grant degrees or conduct exams. They are a supplement to the regular education system, with the aim of nurturing "the whole person." You develop knowledge in a subject you will make use of every day for the rest of your 
life. By taking away the pressure of grades and exams, you learn to motivate and be yourself. You choose the topics that interest you, for instance outdoor life activities, theatre, sports, music, creative arts, media, and communications. Students range in age from eighteen to mid-thirties - most are under twenty-five years of age; approximately one-third are male. School enrollments vary from 50 to 200 over ten months.

\section{Introduction}

There are two kinds of skills that are brought into play when human beings learn. One is perceptual and motor skill; the other is discursive skill. We use perceptual and motor skill to solve problems; we use signs and symbols to interact with others in the social world. The curriculum approach used in formal learning institutions extols the virtues of sign and symbol usage in the pursuit of knowledge. The importance of experience is overlooked and often detached from the learning process as if understanding could be achieved without it.

Research (Harre \& Gillett, 1994) questions the logic behind this separation of learning through experience versus discursive learning. Harre and Gillett describe the natural instinct to learn as starting with the senses, especially the sense of touch. People need to have a "sense of physical location" when they learn. What much educational research fails to address is a fundamental issue in formal education institutions: How do people learn when experience [doing] intervenes, when it precedes or replaces knowledge acquisition?

This ethnography is unique in that it documents what happens to young adults when their learning is undertaken in a non-academic and non-competitive environment. Examples of human learning that are reported in the educational literature too often take place in formal learning institutions, e.g., schools, colleges, universities. The learning reported on here is that of people in a folk school in Norway, a one-year residential program where young adults pursue something other than an institutional milestone. They live and learn away from the comforts of home and the academic culture of a formal school or institution. The case helps articulate what it means to be a self-sufficient learner as a human being. It also helps put the program and professional status problems faced by school educators into a new perspective, one that looks critically at the institution in which the curriculum is taught. Is assimilation into adult life through academic achievement really beneficial to all young people? 
To be an ethnographer the researcher must go to the site or institution in order to observe behaviour in a natural setting, just as an anthropologist who wants to learn about other cultures would do. The term ethnography is most often associated with such observation, or the "ethnographic account," i.e., the documentation. Common techniques associated with data gathering are interview, documentary analysis, life history, investigator field notes, and participant observation (Cole, 1991; Polkinghorne, 1988; Merriam, 1988; Tripp, 1993). The end product is a rich description and interpretation of the institution, sub-culture, and group being studied (Greenfield, 1993). The following statement by Wolcott (1988) captures the essence of what an ethnographer does and how he/she thinks.

To the group being studied, the ethnographer tries harder to know more about the cultural system he or she is studying than any individual who is a natural participant in it, at once advantaged by the outsider's broad and analytical perspective but, by reason of that detachment, unlikely ever totally to comprehend the insider's point of view. (p. 189)

Resolving this tension is the essence of ethnographic work, according to Wolcott. "Successful ethnographers resolve the tension between involvement and detachment; others go home early" (p. 189). Wolcott defines ethnography as describing a "way of life" of some identifiable group. To be successful, he argues, requires a willingness to be part of the culture and have a Martian detachment at the same time. The research in this case did involve total immersion for a period of six weeks. It also involved the reflections of the author, before, during, and following the experience. Interviews, participant journal entries, and author narrative combine to create the documentation.

\section{Author's Reflection}

For years my disappointment with formal learning in schools was centred on the fact that schools prolonged adolescence, unnecessarily I thought. This was confirmed for me when I studied the sociology of education as a doctoral candidate. Now, years later, my disappointment centres on the actual program we offer our adolescents while they are being confined in schools. It seems natural to me that a significant part of that learning should be preparing them for adulthood and for living in some tangible way. The academic curriculum students currently contend with in North America is very university-centred, in fact, singularly so. If you try to follow some other avenue you risk being labelled a low achiever or outsider who doesn't fit. Subjects like music, drama, art, technical and family 
studies, and physical education are accorded a complementary rather than central role in curriculum and policy terms. The program hierarchy in schools is such an everyday part of its history; it goes unnoticed as an equity issue. Students are shunted in and out of courses like sheep in a merry-go-round attempt to broaden their perspectives and give the appearance of equality between book learning and practical endeavors, between contemplation and real life. Yet their perspectives are not broadened. Instead they come to know about standardization, group and institutional conformity, and book literacy. They miss what it means to learn through experience, for oneself. This is the nature and game of the comprehensive secondary school. The difficulty lies with what is prescribed by education authorities as necessary requirements for graduation and entrance to college or university. By the time students schedule their college or university preparation courses, there is little time left to accommodate other programs and ways of learning that may or may not be natural for them and that may meet a fundamental personal need.

I arrived at Fosen Folk School two weeks after the students. It was mid-September. The weather had been beautiful. The journal entry which follows (Signe) and the survey response from Turid convey something unique about Fosen. This is definitely not your typical school. On my first full day there [a Saturday] I joined the students on a hike to the top of the local mountain, a 1500-metre climb, complete with lunch, bagpipe playing, and a determined student with a prosthetic leg. Dewey (1925, 1938) would have enjoyed these excerpts as testimony to his "nature and experience" philosophy, i.e., that "education is life itself." Signe is one of many students who got an abrupt introduction to "life" at Fosen in those early weeks. "No academic expectations here,"I remember many students telling me. No courses on living and learning about life. This is life. No simulations. Imagine the panic when the students in the boat in which Signe was travelling, realized that they faced a life-threatening situation. They had no experience on the North Sea. They had no experience to assure them that this boat could and would withstand the winds and waves. They had only themselves on which to rely for their comfort and safety. These inexperienced students had to stay focused and steadfast in their first adventure of many with Mother Nature as the teacher. Here is Signe's journal entry. All names are pseudonyms.

Rolling against the wind on the ford. One boat, five persons, no teacher. We're all pretty exhausted. Some of us have got big blisters on our hands after hours of rowing. But we can't stop to rest, we have got no time to argue about the job we're doing. We've just got to continue steering straight. On to the waves which are growing bigger all the time. We can't stop until we've made it to the nearest harbour. It's our second week at Fosen Folk School. 
The year here at Fosen is about being nobody but yourself. Perhaps having a fresh start without the emotional luggage we all tend to collect throughout the years. It's about drifting into this small society which is so intense that you sometimes completely forget the outside world. A society where age, sex, and cultural differences are less important, where we try to always see people as individuals.

We learn to know each other like we have never known anyone before. Spending days and nights together at the school, on a sailboat, in the barn. This makes the good times better, but also the bad times worse. Whatever we get into, we're in it together, at least for this one year.

I can allow myself to spend an entire day trying to learn how to do a knot. If I've got three hours of spare time in the afternoon, I might choose to spend them carrying hay bales at the school farm, before learning to play a new song on guitar by one of the other students. In the night I might drift into sleep by a fire in a cozy, hot gamme [outdoor teepee] and wake up freezing at 6 am in the morning.

Folk school is not fun all day long. But everyday I get to feel that I'm really alive.

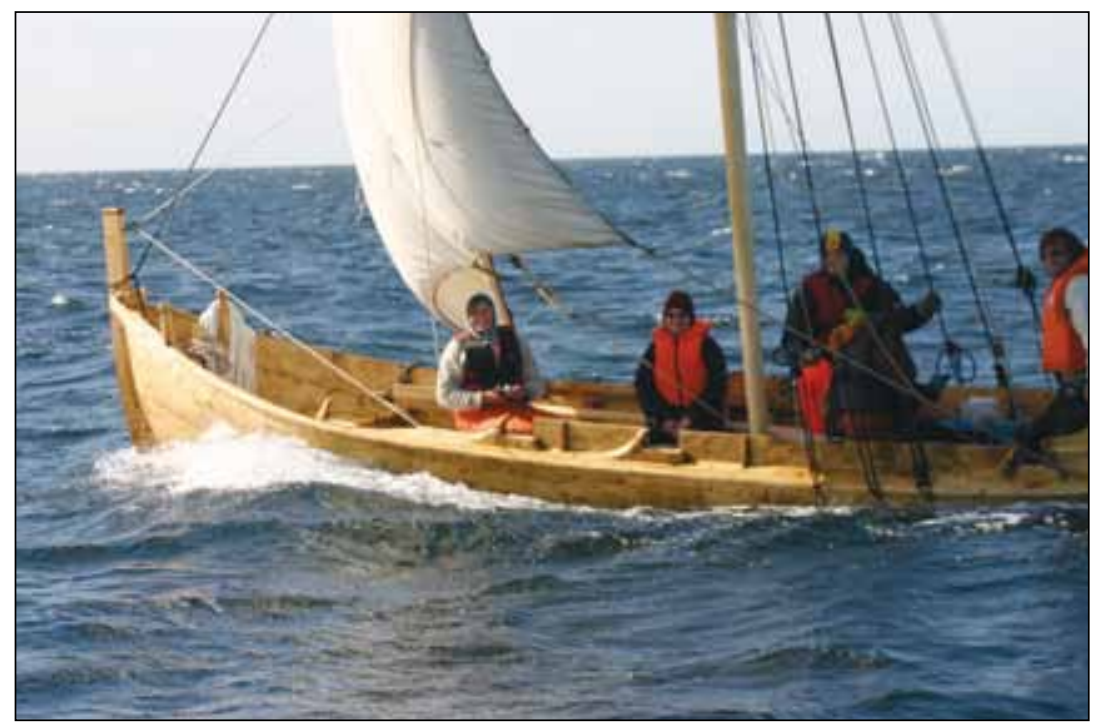

Fig. 1: Sailing excursion for beginners 
Signe had obviously been emotionally moved by her first boating experience. From my perspective she was a bright young woman who wanted to be challenged but had no idea this kind of challenge would be waiting. It was my introduction to a different kind of culture and view of learning, in this instance "learning for life," learning to be self-aware and self-directed.

I could only imagine what was going through the minds of these young adults. Twelve years of schooling did not prepare any of them for this situation. Only an experienced sailor or instructor would know what to expect and be prepared for. This was life on the sea. This was life in a natural environment. This was learning in a folk school, I was to discover as a visiting ethnographer. The questions in my mind were numerous. What was the point of the boating story? Where were they going/coming from? Why wasn't an instructor along? I would have the answers soon enough.

How many times do young people say, the ones who breeze through high school and the ones who struggle, "I just want to take a year off." This ethnography is for those young adults, and teachers who strive to understand them. It provides an inside look at a form of education that stands in direct defiance of the rush to education and economic supremacy by nations. It heralds the importance of human development in a most basic way and at a most fundamental time-young adulthood when values and wisdom are nurtured. The underlying line of inquiry that emerges from the study is captured in the following question: What purpose does the predominant knowledge-oriented curriculum tradition in our schools serve? This analysis of the question criss-crosses the assumptions and premises behind today's change in the education industry and places it in a larger and critical perspective.

The knowledge-oriented tradition as currently legitimized in North American schools enjoys a favoured position because few options to such learning are understood to exist. No words exist to formulate an apposition because as one interviewee put it: "we don't have the experiences from which to make sense of the words." The little-known institution along the coast of Norway, Fosen Folkehøgskole, is but one example of many in the Scandinavian countries that speak to a fundamental issue: What experiences are of most value to young adults as they contemplate their lives and livelihoods? The school is one of ninety-two such institutions that have served Norwegian and international students for over 150 years. ${ }^{2}$

Three themes emerged and are traced in the following written account of the Fosen Case Study. The first is the value of experience as opposed to, or in contrast 
to, knowledge as the real precursor to learner understanding. What is the role of experience in learning and how does "learning by doing" actually happen? The second is a more complete understanding of lifelong learning and how the Nordic people, the inventors of lifelong learning, define and practice it. Finally, the third theme emerges from the social life that students experienced. What happens to young adults when the stressors of academic achievement are replaced by dealing with real consequences?

\section{John the Rektor}

The following excerpt from the Rektor of the school (school principal or headmaster) when asked about a turning point in his career conveys what it means to be human, in this case to be technical or practical. John was my point of contact for visiting Fosen, as such I felt a kinship to him. He had taken my request to visit the school to his staff of nine instructors and formally sought permission to allow a guest from abroad. They must have agreed to accommodate me although some were more cordial than others over the six-week stay. On several occasions when I had specific questions or needs I would seek out John. He was a warm human being. If there was some flattery in having a professor visit he didn't make much of it. Of all the staff he was the only one who lived away from the campus (two kilometres). Often I would see him driving up to the campus in his weather-beaten Volvo. I asked about a turning point in his career.

If there has been a turning point it must have been when I graduated from secondary school. At age of 19 I decided to spend a year at a practical school in a class that worked with building furniture (mobelsnekker). Through that year I got to know the inside of a real handcraft with its standards and qualities. It was very meaningful and from that time I have had this tendency to look upon all things in life the way a carpenter does, which I think is a very useful perspective, because it is both realistic (the chair has to be stable) and aesthetic (a beautiful chair is lovely to own). It responds to all sides of the personality in a way that theoretic subjects often lose.

So when I treat my wife in a carpenter's way or make my lyrics [when playing the piano] the same way or if I run this school according to carpentry standards I think the results often become successful. Besides, my dream is, when I am to retire as an old man, I want to be living as a happy carpenter. In fact this thought helps me going good through my days as a headmaster. 
This excerpt is telling. It is one of the few written accounts from an experienced educator, one formally trained, where his social and technical thinking (S\&TT), was admittedly more important in his career than any other institutionalized learning. It was refreshing to also read about theories he felt contributed to his development as a human being and educator.

As a teacher student (1979-1982) I got to know such names as Paulo Freire and Celestin Freinet and their thinking. I have always meant that schools should be the property of the people and I am very critical to the fact that schools, as other common goods in society, now are made objects exposed to competition between deliverers. There are values in society so important that they should not be measured in money.

I also have become more and more aware of the way the students' total health situation interferes with their ability to learn and grow. Normally we tend to think that personal development goes on only for the first 15-20 years in life, but it seems as if the whole society now is realizing that learning goes on for the whole life. In Norway we talk a lot of lifelong learning, which has become a priority field in education politics. I myself would like to add that this isn't just about lifelong learning but just as well about life-wide and life-deep learning. Let's make education three-dimensional!

In response to how the folk school meets the needs of young adults he was equally compelling in his writing and beliefs.

These human qualities [persistence, life skills, sense of purpose] are in my opinion very important to all people and cultures that intend to survive. Today's young people may have to struggle not against nature or to provide themselves with food and clothes, but rather against the commercialised and meaningless reality of today, and also the great information flood that every day reminds us that some catastrophe is waiting to fall over our heads one day soon.

My hope and belief is that people who get the chance to spend some time training up their practical skills, will be more able to find a way through any problem they have to face on their way through life. That is why Fosen is absolutely needed as a school to our students.

My notes from a brief interview show that John had been teaching in a folk school for fourteen years, six of which had been as Rektor. His speciality is woodworking although he also leads the morning singing sessions with the piano. ${ }^{3}$ 
Walter, a former Rektor at Fosen (I learned from John), was interested in this Canadian visitor and wanted to talk. I was told he was the visionary and founder of the school. ${ }^{4}$ We met for an hour in the student lounge. In spite of our cultural differences we found much in common. We shared stories about the value of life and work experience and about formal learning institutions. I wanted to know more about the nature of the instructors in folk schools. What about the modesty I was witnessing, and the soft-spoken nature of almost everyone. What was the source of this modesty?

The question turned out to be an important one as it opened up a discussion about how people learn. Walter, like the instructors at Fosen, believed their job was to instil a broader perspective (life learning) in students than that given in regular school. He introduced me to several Norwegian concepts, one of which was "Vok." Apparently, in 1976 the law in Norway changed and education was provided free to all adult people (lov - law om voksenopplaring). In North America, the parallel would be to make adult education tuition free to all adults. Walter started his career at Fosen in 1978. He felt he was part of a new effort in Norway to humanize and democratize the formal education system for young adults.

"Learning for life" was the phrase he used to describe the movement. It meant several things-one was learning with and from other people. The boat-building program was one example he cited. The school wanted to preserve and celebrate the original Viking boat construction designs and skills from ten centuries earlier. Part of passing along that culture included how skills and knowledge were passed on. In this case, as with all other subjects/activities in the school, that method involved giving youth answers only when they were ready for them. First-hand experience was the bedrock of the learning philosophy at Fosen. Knowledge and wisdom followed. To re-establish the dying boat-building history they found the last person known to apprentice under a master boat builder (of original Viking boats) in remote northern Norway and hired him to come and live in their community. Part of the philosophy for learning was that young people should learn to stay focused on the problem at hand. To do this the students who enroll in boat-building must build and sail a boat while they are in the program.

I inquired about certification and training of teachers in folk schools. There were no credentials initially; now there are. Above all else work experience is important, teacher education is secondary. At Fosen the preference is to find teachers who have experience in their field, whether it be boat-building, sailing, woodworking, natural life (science), or farming. The word pedagogy came up. Walter felt that the language for pedagogikk (the Norwegian spelling) was unemotional and empty. Why 
is it that we teach like we do in regular schools? Why don't we try something else? He eschewed "model thinking." To help explain the Fosen approach he referred to the concept of a Kibutz in Israel. The term means "learning on the farm." You must have both theory and practice to get respect. Another example he mentioned is captured in the fine art of music instrument building. To build the finest violin possible the artisan must be one with his/her tools and know the physics of sound. It is the same experiential learning view. A person must be capable of technical thinking and learning.

He described another key principle called "Variety and Time" (Mangfold og Tid). Part of this perspective is to never strive to be something special or at least to think of yourself as something special. This helped to explain the modesty I was witnessing around the school. No one here is trying to upstage anyone else or to be special. They are who they are.

Walter described schools as unhistorical. I asked what he meant. "They have no respect for local history," he said. I know now what he meant. The widespread use of a prescribed and standardized curriculum requires schools to focus on regional and national histories rather than local ones. This is very true in most history courses in North American schools. ${ }^{5}$ Part of the pedagogy associated with the Fosen learning philosophy includes using pictures as well as experience rather than words. In Nordic mythology, local history is told poetically using dialogue and narrative. In science, students have to start with the tree first then its name. This is what fits human nature best. He felt that teaching science out of a textbook was a less than useful strategy for helping young people to learn about science concepts, laws, and so forth. The student needs to "experience" the phenomena before he or she can digest and understand the words that label or describe it. Walter referred to a former Norwegian Minister of Education (Godmund Hernes), who in 1995, told an international gathering that the greatest contribution Norwegians have made to the world of pedagogical thought is the Folk School. I now know where the modesty comes from and how it fits.

\section{Morton the Natural Life Instructor (Science)}

Morton offered to have me join him for coffee at noon (this usually means something more than coffee in Norway - this time it was waffles with sour cream and fresh strawberries plus coffee). The interview was in his apartment adjacent to the school premises. 
In addition to explaining some Norwegian terms and filling out my interview sheet he expanded on his philosophy as an instructor. He described his method of instructing by using the concept of a continuum. On the one end of the continuum he is someone who gives a lot of direction and information ["like a dictator" - his words]. On the other end he is someone who gives little information to the students. He describes this end of the continuum as "veiledning." The closest word for us in English is "facilitator" but he tells me that this is still not quite right. At the veiledning end of the continuum the students are completely self-directed. He is available to them but only when they have questions and even then in a limited or special way. I probed this only to uncover an old maxim that a colleague taught me years ago. Apparently as an instructor, Morton only responds to the students' questions when he feels they are "adequatio" or ready. He mentions that the signal for this is when students ask the good question. Morton's philosophy is to always seek the veiledning end of the continuum.

I am reminded of my discussion with Elmer [boat-building instructor] and how he watched the students shape the twenty-nine-foot boat keel for the original Viking boat. What is this I am witnessing? Is it self-directed learning? Project learning? Do we have words for it in our North American schools? He [Morton] brings out a page of paper on which is typed a poem in Norwegian, by Hans Borli, dated 1969.I had it translated two weeks later.

You and the tree, a brotherhood/sisterhood

Deep as the soil

In the rush of sap

Under the bark

Your (own) dream rising

Dizzy, hesitating

In winding stairways of darkness

Up to the face of god

You stand there in Spring Wind

With ear pressed against rugged bark

And suddenly

You know whether it is you

You realize that you see the tree and the tree sees you

My notes refer to the "veiledning" concept but also to a point that Morton made about admission to a folk school. There are no admissions criteria, no sorting of files and people. It is a first-come, first-serve admissions policy. As such, students 
decide. No meritocracy here, just self-selection. My notes from the interview itself start with some demographic information. Morton had been teaching for five years plus two years with handicapped youth. He worked in the logging industry for one year and came from a farming family. His formal preparation for teaching in a folk school consisted of a short program (one year) that granted him a teacher certificate. For a short time he taught skiing in a gymnasium [high school]. His postsecondary education included one year of study in geography and two in outdoor life. Referring to life at Fosen Morton used the words, "Fosen is distinctive."

It is very stimulating to teach here-they know what they are doing. Folk schools are rebels [in the Norwegian education system] in a positive sense, especially Fosen. The main goal for students in most folk schools is recreation. At Fosen it is more meaningful.

In describing his philosophy of teaching he referred to an exercise that he does with his students each year, early on. He takes them into the countryside as a group and sends them out to find a tree. They are instructed to sit beside the tree for twenty minutes, feel the bark of the tree, get in touch with it. He then asks them to return to a point some metres from their respective tree, blindfolds them, and sends them out to find their tree. With great satisfaction he asks me what percentage of the students do I think actually find the same tree. A very high percentage, he tells me. The point of the exercise is to help students make a connection to nature, to get their own personal relationship with nature. "It's not about being better in that relationship than others," he reiterated [part of his philosophy that learning must be done in a non-competitive environment, unlike most schools]. "Nature is not to be challenged, but respected." It turns out that this is the philosophy adopted by not only Morton but also by the former Rektor Walter [notes from interview with Walter]. Such a philosophy maintains that any teaching should start with an experience, followed by book learning. This allows the student to be ready or adequate and thereby motivated for the information that follows, i.e., to know something about the subject personally before words are put to it. Referring to the students who come to Fosen, Morton repeated a common refrain, "I can see that the students are bored from competition in schools [regular schools]."

I inquired about working and learning in institutional settings.

A difficult question, he smiled. Mainly, it's how our society has come to be competitive in all ways. There are few arenas where you do things that can't be compared to others. These arenas are extremely valuable. "Nature life" is one of 
them. I'm also convinced that we are losing many old techniques today, because we are so extremely focused on the future. I think that's a big mistake. In my subject I can do something about it. By learning about ancient techniques, I hope the students can see how complex and advanced they were.

Of the five students who responded to a journal-writing request, Turid's reflections may be the most typical. They are particularly important to what may be a widespread young adult perspective today, in Norway and beyond.

When I was in the secondary school I was sick and tired of studies and books, so my aim or thought was to try folkehogskole, and when I decided I only had Fosen in my head. I know many that have gone to Fosen and they spoke with giant good feelings about it. The Fosen school is very well known in the surrounding area where I live. My two sisters graduated in agriculture and they are happy I choose this school. As a student in Ph. Ed, running, etc., I felt I had to get away from the pressure of training. Last year I had problems with a bad infection. This school does not focus so much on training and that makes me feel good, and I enjoy trips, hiking, and sailing. When I choose this school I knew fellow students would enjoy a different life-they dress differently (funny) and nobody would say anything bad about it-rather they make fun of it. I also enjoy what this school gives-the culture and tradition with instruction. We learn not to take anything for granted. If a boat is to be built, one has to go in the forest and fall trees, so most of the teaching is practical. This is good for those who don't like theory. They get to be good at something. This school also aims at ecological thinking. For example, using ecologic food with the aim of a strong economy. There is practically nothing I don't like at Fosen school.

I have been at this school only one month but I know when I leave next Spring, I will miss this school very much.

Sincerely, Turid

This testimony is particularly germane in the context of curriculum priorities for formal secondary schools. The pressure to prepare for some unknown knowledge discipline places undue pressure on young people before they know who they are and what they want to become. An interview with the school nurse confirmed this need for self-analysis and sense of accomplishment. 


\section{Marit (Part-Time Nurse)}

The meeting with Marit took place in her office at the local health clinic/ hospital (about one-half kilometre from the Folkschool). I had telephoned a few days earlier to make an appointment.

Marit sees students from the school but only on a part-time basis. There is the occasional student injury to deal with (Ellen sprained her ankle, for example), but most of her visits are from the younger students who are away from home for the first time and feeling homesick or lost. This counselling function seemed to be something with which she was comfortable. I had noticed a good deal of boy/girl cuddling in the time I had been at the school and wondered if showing such affection in public was considered cool/normal behaviour in Norway among adolescents. Marit characterized such behaviour as quite normal, even to the extent of sexual involvement providing the participants were over eighteen years of age. Apparently the law in Norway is that when a person reaches age 18 they are considered a mature adult in Norwegian society and are then responsible for their own actions. I asked her to characterize the young students at Fosen. "They are scattered in their thinking. They don't know where they are going because they don't know where they have been or who they are, what they believe in for sure." About the folk schools she commented: "It allows these 'adults-in-transition' to develop questions from a range of areas, work interests, personal morals, social relations they had not thought of as yet. It gives the students a year in which to grow outside of their usual home surrounding and support network. For the first time in their life no academic expectations removes an important and nagging stressor." According to Marit, the result is that they have more time to think about problems. Because of the life and human-centred curriculum at the school and the many experiential projects/workshops, they build self-esteem and self-confidence.

I was quite emotional the day I left Fosen. My reflections mirror those from the beginning of this collaborated story (Connelly \& Clandinin, 1990, 2000). How can life in schools, or the absence of it as John and Walter would say, be analyzed through students' stories? The following thoughts were documented while on the ferry from Fosen to Trondheim.

The road sloped gently down towards the village of Vanviken. Roald [Fosen student who drove me to the boat] is his usual self, full of the wisdom that made our discussions special. "For the first time in my life I feel free," he said. More wisdom, I thought. 
As I write I am not sure what I said to Roald. How is an ethnographer supposed to keep track of conversational material on the one hand and record and reflect on the moment too? To do the three things at the same time is complex, as Wolcott's quote suggests. I must have told Roald I liked those words because I remembered to write them in my journal while on the ferry. I also probably listened because during all of our conversations over the six weeks I found his thoughts and actions to be mature beyond his years. I must try to capture that sensibility in words and to tell Roald's story. But first the "free" part and why these words.

\section{Roald's Story}

My introduction to Roald was on my first trip with the student group at Fosen. Fosen is located in a small community known as Rissa, population 2,000. Picture a small rural town nestled among rolling farmlands and surrounded by northsea fjords (gentle-sloped ones). While this might sound isolated, it isn't when you live here. The Norwegian people are sure-footed (physically active in the outdoors), sureminded (self-assured and practical), and hospitable when they befriend you.

Roald climbed up a 1500-metre (4500-foot) local mountain with all the other students, a little behind but not far. He did so with one prosthetic leg. I didn't really meet Roald that day but noted that he made the trip successfully and without any help from fellow students or instructors. In fact, I was struck by how aloof the instructor was that day, about all the students. He was responsible for leading the expedition but didn't make any special attempts to help specific students. It was clear that each student was responsible for his or her own actions. Even when three of the slower students asked permission to return to the school from the first rest point, he didn't seem bothered or disappointed. When I asked him about that conversation he said simply, "it is their loss." I was concerned about the possibility of others taking the path of least resistance (no pun intended) and returning to the comforts of the school and the valley floor. I later learned that this decision was part of a school-wide, perhaps even a society-wide, philosophy. The students are adults and are responsible for their own actions. No handholding or prodding here.

I came to know of Roald's maturity during many moments in the student lounge when students would socialize, be themselves. Roald wasn't interested in small talk among peers and outward showing of affections between boys and girls. He enjoyed being by himself or with friends in situations where he could learn or be challenged intellectually. He would play contract bridge with a group of us, or chess, or spend time in the wood shop, carving. 
It was several weeks after I had left Fosen that I wrote to him and asked if he would consider telling me the circumstances about his leg. Roald's maturity had come, in part, through a life-threatening football injury that was eventually diagnosed as cancer. He came close to losing his life at age fourteen. Subsequently, he chose to follow an interest in boat building at Fosen. The wisdom from that experience gives perspective to what counts in life. But, why would an experience like this be thought of as "being free"? Free from what? Free from the cancer? Or, free from the existence of student life in a formal school? Roald had freed himself from both-two very significant and equally crucial life-changing experiences. John's point about lifewide and life-deep learning may be more crucial than I thought. The "life" in lifelong learning is just as important as the "long."

Analyzing social behaviour is not something with which this author is comfortable. I can't help but wonder how much of the student desire to be free, in Norway or elsewhere, has to do with a rebellion against institutionalized learning (Hansen, Carter, Gurney, \& So, 2002) and on a societal acceptance of institutional solutions to individual, family, and community problems (leave it to or rely on the expert-a kind of abandonment of emotional and self-sufficiency-an oblivion).

This paper set out to improve understanding of informal learning through experience, and how it impacts on human development. How does such learning/ thinking empower and liberate people? How does it enhance or restrict individual growth? The case puts institutionalized learning into a fresh perspective. The result is a new understanding of "learning and personal development." How much formal vs. informal learning should young people be encouraged to sustain? What is the role of experience in one's learning and development? Should school systems embrace a model of learning that values experience as well as knowledge? Will/should the influence of nature on learning be a factor in our thinking as educators? 


\section{Notes}

1. Adapted from a previous report written by the author in 2004, entitled, "The Influence of Nature on Learning: A Year to Be Free (Report From Field Studies in Fosen, Norway)".

2. Grundtvig (1789-1872) is credited with developing the philosophy and setting the stage for a unique kind of learning (Borish, 1991). Called "Schools for Life," the folk schools don't denounce the importance of knowledge, they just place experience before it as the foundation upon which to learn and to practice democracy in a society. The predominant view that experience is but a complement or adjunct to the more important academic curriculum that pursues the acquisition of "knowledge," is challenged.

3. The student body meets each morning for planning and socializing. Part of that meeting includes joining voices in song. Another includes information sharing on school projects, another the sharing of stories by one another (usually in a thematic way articulated by the instructional team but involving the students).

4. Walter had been retired for several years. When he heard [word travels fast when a stranger arrives in a small community] that I was a visiting professor he expressed an interest in being a part of my research. That interest was genuine.

5. Folk schools don't have to adopt a standardized curriculum. As such, the important history and culture associated with boat-building in Norway was chosen as a goal by Fosen so that this important tradition could be preserved and celebrated. Youth learn about their history firsthand through intimate experience.

\section{References}

Borish, S. M. (1991). The land of the living: The Danish folk high schools and Denmark's non-violent path to modernization. Nevada City: Blue Dolphin Publishing, Inc.

Cole, A. L. (1991). Interviewing for life history: A process of on-going negotiation. In Ivor Goodson and Marshall Mangan (Eds.), Qualitative educational research studies: Methodologies in transition, Vol. I, (pp.
185-209). Research Unit on Classroom Learning and Computer Use in Schools, Occasional Papers, Faculty of Education, The University of Western Ontario, Canada.

Connelly, F. M., \& Clandinin, D. J. (1990). Stories of experience and narrative inquiry. Educational Researcher, 19, 2-14. 
Connelly, F. M., \& Clandinin, D.J. (2000). Narrative inquiry: Experience and story in qualitative research. San Francisco: Jossey-Bass.

Dewey, J. (1925). Experience and nature. New York: WW Norton \& Company Inc.

Dewey, J. (1938). Experience and education. New York: MacMillan.

Greenfield, T.B. (1993). The man who comes back through the door in the wall: Discovering truth, discovering self, discovering organizations. In T. Greenfield \& P. Ribbing (Eds.), Greenfield on educational administration: towards a humane science (pp. 92-119). London: Routledge.

Hansen, R., Carter, K., Gurney, B., \& So, M. (2002). Comprehensive Secondary School Pilot Study. London, ON: The University of Western Ontario, Faculty of Education.
Harre, R., \& Gillett, G. (1994). The discursive mind. London: Sage Publications.

Merriam, S. B. (1988). Case study research in education: A qualitative approach. San Francisco: Jossey-Bass.

Polkinghorne, D.E. (1988). Practice and narrative. In Narrative knowing and human sciences. (pp. 157-184). Albany: State University of New York Press.

Tripp, D. (1993). Critical incidents in teaching, London: Routledge.

Wolcott, H. (1988). Ethnographic research in education. In R.M. Jaeger, (Ed.), Complementarymethods. (pp. 185-206). Washington, DC: American Educational Research Association.

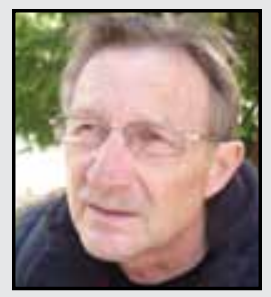

Ronald Hansen is a technology teacher educator and researcher who analyzes and questions the assumptions and premises upon which school systems in Ontario are based. His research explores the relative value of life and work experience in apposition to academic learning. In a policy development context these two forms of learning are visible and invisible to the general student population and the public. A critical look at formal education systems provides Dr. Hansen with an opportunity to consider alternative curriculum designs for institutions and the people who inhabit them. His work challenges education leaders and mainstream policies which govern and sustain the momentum enjoyed by government-controlled institutions.

\section{LINKTO:}

www.fosen.fhs.no 